\title{
Diagnóstico ambiental simplificado na área de preservação permanente do Rio Piancó no semiárido Paraibano
}

Neste trabalho objetivou-se realizar um diagnóstico ambiental simplificado na Área de Preservação Permanente (APP) no trecho do Rio Piancó, situado na área urbana de Pombal - PB. A metodologia utilizada teve por base pesquisas bibliográficas em fontes científicas e técnicas, visitas a campo, fotodocumentação e consultas a órgãos públicos. Para tanto, fez-se o georreferenciamento da área a partir de ferramentas de geoprocessamento, em seguida, foi realizado um diagnóstico ambiental simplificado da área de influência desta pesquisa. De acordo com os resultados obtidos, verificou-se a ocorrência de várias alterações ambientais adversas significativas nos meios físicos, bióticos e antrópicos, ocasionadas pelas a atividades antrópicas na APP do rio, destacando-se a urbanização e a pecuária. Por fim, espera-se que os resultados obtidos nesse estudo sirvam como base para estudos futuros na APP do rio Piancó, principalmente no trecho urbano de Pombal - PB.

Palavras-chave: Degradação ambiental; Mata ciliar; Avaliação de Impactos Ambientais (AIA)

\section{Simplified environmental diagnosis in the permanent preservation area of the Piancó River at the Paraibano semiarid}

This work aimed to carry out a simplified environmental diagnosis in the Permanent Preservation Area (APP) on the stretch of the Piancó River, located in the urban area of Pombal - PB. The methodology used was based on bibliographic searches in scientific and technical sources, field visits, photocumentation and consultations with public agencies. For that, the area was georeferenced using geoprocessing tools, then a simplified environmental diagnosis of the area of influence of this research was carried out. According to the results obtained, it was verified the occurrence of several significant adverse environmental changes in the physical, biotic and anthropic environments, caused by anthropic activities in the APP of the river, especially urbanization and livestock. Finally, it is expected that the results obtained in this study will serve as a basis for future studies in the Piancó River APP, mainly in the urban section of Pombal - PB.

Keywords: Environmental degradation; Riparian forest; Environmental Impact Assessment (EIA).

Topic: Engenharia Ambiental

Reviewed anonymously in the process of blind peer
Received: 06/04/2021

Approved: $27 / 04 / 2021$
José Ludemario da Silva Medeiros (iD) Universidade Estadual da Paraíba, Brasil http://lattes.cnpq.br/4084311510300833 http://orcid.org/0000-0002-7523-9601 joseludemariomedeiros@gmail.com

Jair Barros Agra Filho

Universidade Federal de Campina Grande, Brasil http://lattes.cnpq.br/4211929747315135 jairbarros18@hotmail.com

luri Souza de Jesus (it)

Universidade Federal de Campina Grande, Brasi http://lattes.cnpq.br/9940532745543327

http://orcid.org/0000-0003-0902-2997 moixaiuri@gmail.com
Tássio Jordan Rodrigues Dantas da Silva (iD Universidade Estadual da Paraíba, Brasil http://lattes.cnpq.br/1991160864996557 http://orcid.org/0000-0002-1708-5472 tassiojordan@hotmail.com

Maxsuel Bezerra do Nascimento Universidade Estadual da Paraíba, Brasil http://lattes.cnpq.br/7100621157794567 http://orcid.org/0000-0001-6381-2688 maxsuel10gba@hotmail.com

Andreia Freitas Silva

Universidade Estadual da Paraíba, Brasil http://lattes.cnpq.br/2919183251860456 http://orcid.org/0000-0002-3737-5856 andreiafreitassilva@gmail.com
Janaína Aparecida Cezario (iD

Universidade Estadual da Paraíba, Brasil http://lattes.cnpq.br/2080075497375535 http://orcid.org/0000-0002-9866-4168 a nayna2@yahoo.com.br

José Cleidimário Araújo Leite (iD

Universidade Federal de Campina Grande, Brasil http://lattes.cnpq.br/7938270564009075 http://orcid.org/0000-0001-6750-3495 cleidimario@yahoo.com.br

\section{William de Paiva}

Universidade Estadual da Paraíba, Brasil http://lattes.cnpq.br/26129779883185686 http://orcid.org/0000-0003-0220-1247

w.paiva461@gmail.com
Referencing this:

MEDEIROS, J. L. S.; AGRA FILHO, J. B.; JESUS, I. S.; SILVA, T. J. R. D.; NASCIMENTO, M. B.; SILVA, A. F.; CEZARIO, J. A.; LEITE, J. C. A.; PAIVA, W.. Diagnóstico ambiental simplificado na área de preservação permanente do Rio Piancó no semiárido Paraibano. Revista lbero Americana de Ciências Ambientais, v.12, n.4, p.382-398, 2021. DOI: http://doi.org/10.6008/CBPC2179-6858.2021.004.0030 


\section{INTRODUÇÃO}

Ao longo do tempo, a grande maioria dos centros urbanos desenvolveram-se às margens de rios, o que ocasionou a destruição das matas ciliares (vegetação natural que margeia os cursos d'água), e hoje como consequência desses atos, associados a outros fatores, ocorrem as enchentes que atinge a população que moram próximo a esses corpos d'água.

Segundo o novo Código Florestal Federal, Lei n.12.651, de 25 de maio de 2012, as matas ciliares são Áreas de Preservação Permanente (APPs). Essas áreas são de extrema relevância, em relação à conservação da água e são consideradas espaços nos quais a vegetação deve encontrar-se intacta para garantir a preservação dos recursos hídricos, a estabilidade geológica e a biodiversidade ser mantida e preservada (BRASIL, 2012).

De acordo com Alemu et al. (2017), a vegetação ripária constitui uma zona de transição entre os ecossistemas aquáticos e terrestres e fornece muitas funções, incluindo a redução do carregamento de sedimentos, o controle de processos erosivos, além de fornecer sombra e habitat para organismos, sendo também essencial para diminuir os impactos negativos sobre o solo.

Segundo Correia et al. (2019), a mata ciliar funciona como um obstáculo natural ao escoamento das águas, diminuindo seu impacto direto no solo, evitando assim que as partículas sólidas sejam arrastadas e depositadas no leito dos rios, assoreando-os, sendo de fundamental importância para a manutenção e qualidade dos recursos hídricos e servem de abrigo e fonte de alimentação para a fauna terrestre e aquática.

A presença da vegetação ciliar influencia diretamente na bacia hidrográfica, já que as suas funções e efeitos positivos refletem na boa qualidade de vida das populações e no equilíbrio do meio ambiente, no entanto, a sua preservação é um dos fatores primordiais (CASTRO et al., 2017).

Neste contexto, tal realidade de destruição da mata ripária ocorreu em diversas regiões do Brasil, principalmente na região semiárida do nordeste brasileiro. Diante disso, de acordo com a Agência Executivas de Gestão das Águas do Estado da Paraíba (AESA), na Bacia Hidrográfica do Rio Piancó-Piranhas-Açu, situada na região semiárida brasileira, que abrange parte dos estados da Paraíba - PB e do Rio Grande do Norte - RN. Portanto, há diversos problemas relacionados à ação antrópica, sendo os principais, segundo o Comitê da Bacia Hidrográfica do Rio Piancó-Piranhas-Açu - CBHPPA: contaminação das águas, assoreamento pelo uso inadequado do solo, degradação da mata ciliar, erosão generalizada e escassez hídrica.

Deste modo, os estudos ambientais surgem como uma importante ferramenta para controlar essa problemática, por exemplo, a Avaliação de Impactos Ambientais (AIA), que pode incluir desde o diagnóstico ambiental da área até o Plano de Recuperação de Áreas Degradadas (PRAD), sendo o primeiro, uma base para a confecção e execução do segundo. O diagnóstico tem por finalidade principal descrever e analisar a situação ambiental atual de uma área na qual, em geral, haverá a implementação de um empreendimento ou outra atividade antrópica.

Diante do contexto abordado, este trabalho teve como objetivo propor um diagnóstico ambiental simplificado dos meios físicos, bióticos e antrópicos da Área de Preservação Permanente (APP), no trecho 
urbano da cidade de Pombal no estado da Paraíba.

\section{MATERIAIS E MÉTODOS}

\section{Localização da área de estudo}

A área de estudo situa-se na região Oeste do estado da Paraíba, segundo a divisão do Instituto Brasileiro de Geografia e Estatística (IBGE) vigente, na Região geográfica intermediária de Patos - PB e na Região geográfica imediata de Pombal - PB (IBGE, 2017), no trecho perenizado do rio Piancó, na área urbana de Pombal - PB, conforme ilustrado na Figura 1.

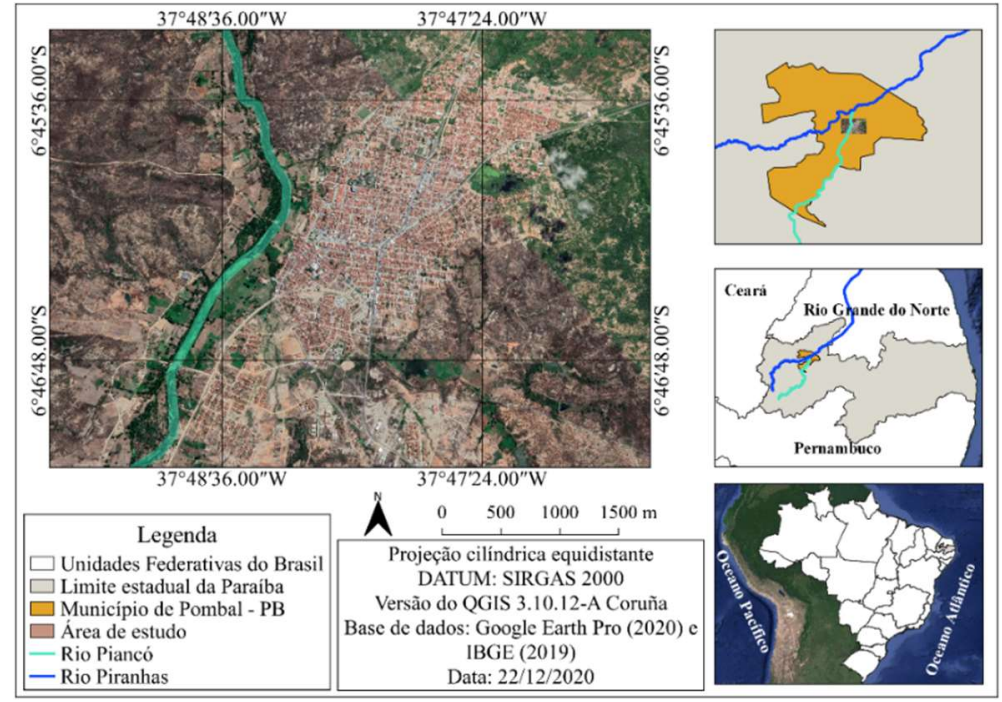

Figura 1: Localização da área de estudo.

\section{Definição da área de influência do estudo}

A área de influência do estudo encontra-se no trecho perenizado do Rio Piancó que corta parte da área urbana do município de Pombal - PB, entre as coordenadas geográficas de latitude, $S 6^{\circ} 47^{\prime} 12,88^{\prime \prime}$ e $S$ $6^{\circ} 45^{\prime} 45,97^{\prime \prime}$, e longitude, W $37^{\circ} 48^{\prime} 54,74^{\prime \prime}$ e W $37^{\circ} 48^{\prime} 24,67^{\prime \prime}$, respectivamente, possuindo aproximadamente $3 \mathrm{~km}$ de extensão.

A área de influência deste estudo foi definida com base na área de mata ciliar no trecho do rio em questão, no que preconiza a Lei n.12.651, de 25 de maio de 2012, que instituiu o "Novo Código Florestal" brasileiro (BRASIL, 2012). Assim, a área de estudo foi dividida em Área Diretamente Afetada (ADA), Área de Influência Direta (AID) e Área de Influência Indireta (All). Logo, as referidas áreas foram definidas com base em critérios teóricos (conceituais/didáticos) e técnicos, conforme exposto na Tabela 1.

Tabela 1: Critérios adotados para a definição da área de influência do estudo.

\begin{tabular}{|c|c|}
\hline $\begin{array}{ll}\text { Área } & \text { de } \\
\text { influência' }\end{array}$ & Critérios para definição da área \\
\hline ADA & Consiste na área que sofreu intervenções efetivas e o ambiente foi modificado ocasionado pelas atividades antrópicas. \\
\hline AID & $\begin{array}{l}\text { Área onde ocorrem os impactos ambientais diretos, e parte dos indiretos, sobre as águas do rio, resultantes de atividades } \\
\text { antrópicas na área de influência e até próximas a esta área. }\end{array}$ \\
\hline All & Área onde estão situadas as atividades antrópicas que ocasionam impactos ambientais diretos e indiretos nas águas do rio. \\
\hline
\end{tabular}




\section{Georreferenciamento da área de influência}

O georreferenciamento da área de estudo foi realizado por meio da utilização de imagens do Google Earth Pro e de shapefiles, fornecidos pelo IBGE (2015), e do software Qgis (versão 3.10.12 - Acoruña), a partir do qual foram construídos mapas da área de influência.

A partir dos dados e informações obtidas em campo e das ferramentas utilizadas no estudo, foram construídos mapas georreferenciados da área de influência do trecho do Rio Piancó, de uso e ocupação do solo e com indicação dos pontos ao longo desse trecho mais impactados do rio.

\section{Construção do diagnóstico ambiental simplificado}

O diagnóstico ambiental simplificado foi elaborado por meio de visitas técnicas na área de estudo, fotodocumentação e de pesquisas bibliográficas para a fundamentação metodológica. Portanto, nesta etapa buscou-se descrever o máximo possível dos componentes e dos fatores ambientais, suas relações e interrelações na área de influência da pesquisa, para os Meios biótico, abiótico (Físico) e antrópico, conforme apresentado na Tabela 2.

Tabela 2: Componentes ou fatores ambientais analisados no diagnóstico ambiental.

\begin{tabular}{ll}
\hline Meio & Componente ou fator ambiental \\
\hline & Clima \\
& Relevo \\
Físico & Geologia \\
& Solos \\
& Recursos hídricos \\
& Uso e ocupação do solo \\
& Paisagem \\
\hline \multirow{2}{*}{ Biótico } & Flora \\
\hline \multirow{2}{*}{ Antrópico } & Fauna \\
\hline
\end{tabular}

\section{RESULTADOS E DISCUSSÃO}

\section{Definição da área de influência}

As informações sobre a definição da área de influência do estudo encontram-se expostas na Tabela

3.

Tabela 3: Critérios adotados para a definição da área de influência do estudo.

\begin{tabular}{ll}
\hline $\begin{array}{l}\text { Área } \\
\text { influência }\end{array}$ & de \\
\hline ADA & Área que abrios para definição da área \\
\hline AID & Área de entorno do leito do trecho perenizado do riancó (100 $\mathrm{m}$ a partir de cada margem). \\
\hline All & $\begin{array}{l}\text { Área de entorno do leito do rio Piancó (300 m a partir de cada borda da calha do leito regular, ao longo do } \\
\text { trecho perenizado), incluindo a área urbana de Pombal - PB. }\end{array}$ \\
\hline
\end{tabular}

\section{Georreferenciamento da área de influência}

As áreas de influências do estudo, ADA, AID e All, encontram-se na área urbana do município de Pombal - PB, conforme pode ser observado na Figura 2. 


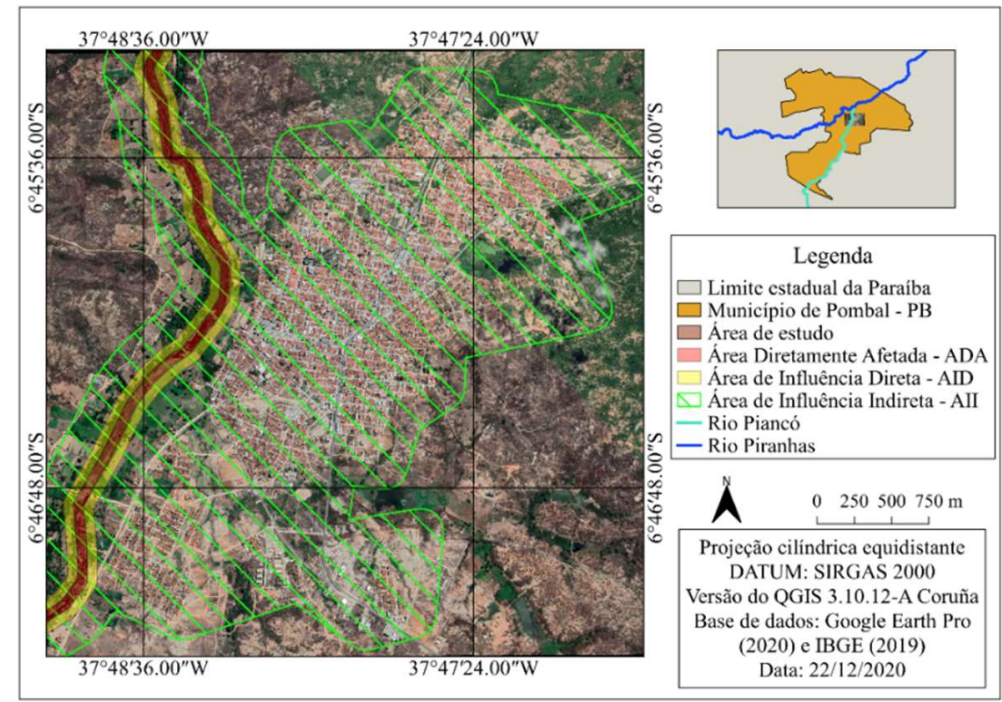

Figura 2: Mapa de localização da área de influência do estudo.

\section{Diagnóstico ambiental simplificado da área de influência}

\section{Meio físico}

\section{Clima}

As informações sobre algumas características climáticas do município de Pombal - PB, como tipo de clima e pluviosidade, estão expostas na Tabela 4.

Tabela 4: Características climáticas da área de estudo.

\begin{tabular}{ll}
\hline Características & Pombal - PB \\
\hline Tipo de clima da região- Classificação de Köppen & - BSh (Semiárido, quente e seco) \\
\hline & - Média anual: $837,5 \mathrm{~mm}$ \\
Precipitação - Período: (2000 - 2016) & - Mediana: $826,3 \mathrm{~mm}$ \\
& - Máxima: $1500,1 \mathrm{~mm}$ \\
& - Mínima: $278,9 \mathrm{~mm}$ \\
\hline
\end{tabular}

\section{Relevo}

O relevo é considerado por alguns autores como o principal fator na perda do solo por erosão, principalmente no que se refere à declividade e ao comprimento da encosta (VALLADARES et al., 2012).

A declividade do terreno contribui para o escoamento das águas, pois quanto maior for o trecho em declive, maior será o escoamento da água pela superfície, arrastando outros materiais para os recursos hídricos superficiais, influenciando a qualidade da água e a infiltração e nos processos erosivos fluviais e pluviais, assim como na tipologia da vegetação, bem como contribui para a formação do solo e serve de indicador na definição de áreas de risco e restrição de uso (GARCIA et al., 2020).

No tocante ao relevo do município de Pombal - PB, a Figura 4 ilustra a representação do relevo da área de estudo, verificando-se faixas de relevo de plano a escarpado.

Na Tabela 5, com base na Figura 4, constata-se que o relevo predominantemente na área de influência do estudo, classifica-se como suave-ondulado, com cerca de $43 \%$, o que corresponde a 37,8 mil ha. Cerca de 59\% (52 mil ha) da área total apresenta declividades que classificam o relevo de suave ondulado a forte-ondulado. Declives menores 3\% ocorrem em aproximadamente 34,2\% (31 mil ha) da área, onde o 
relevo é plano e esses locais geralmente concentram-se próximos aos cursos fluviais, nos leitos ou nos campos de várzea.

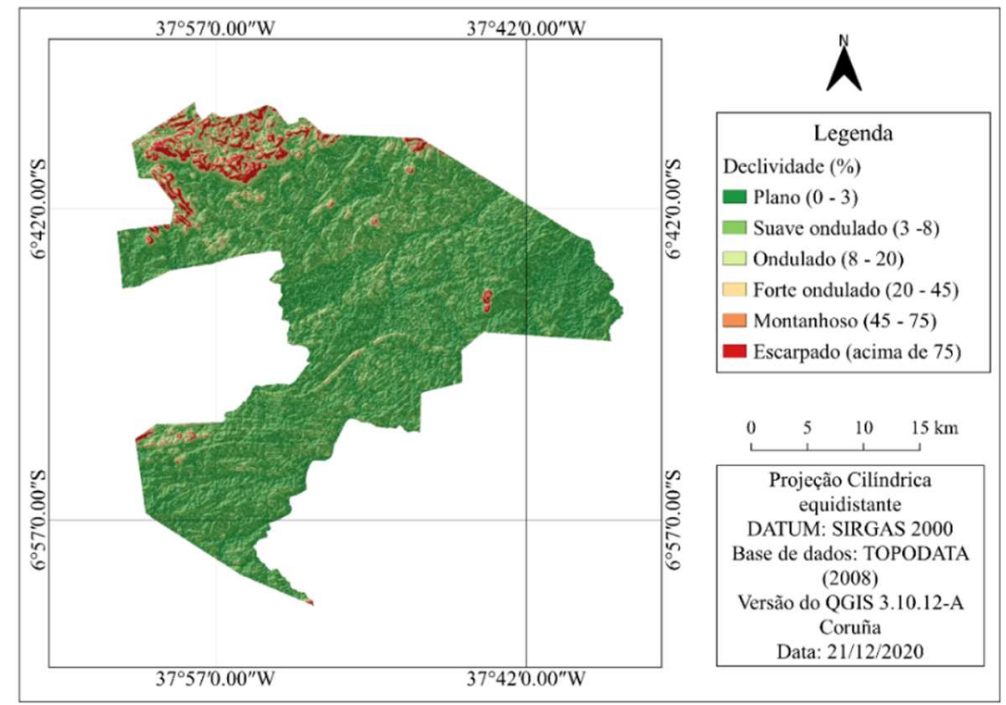

Figura 4: Mapa do relevo no município de Pombal - PB.

As faixas de relevo montanhoso e escarpado, abrangendo somente 1,5\% (110 ha) do território. As áreas mais declivosas com valores superiores a 45\% determinam áreas com uma vertente bastante inclinada com altas suscetibilidades à erosão, não sendo recomendadas para o uso agrícola.

Tabela 5: Intervalos de Declividade com respectivas denominações das classes, áreas e porcentagens correspondentes a cada uma, no município de Pombal, Paraíba.

\begin{tabular}{llll}
\hline Declividade (\%) & Relevo & Área (ha) & \% \\
\hline $0-3$ & Plano & 30.091 & 34,2 \\
$3-8$ & Suave ondulado & 37.785 & 42,9 \\
$8-20$ & Ondulado & 14.200 & 16,1 \\
$20-45$ & Forte ondulado & 4.582 & 5,2 \\
$45-75$ & Montanhoso & 1.233 & 1,4 \\
$>75$ & Forte montanhoso ou Escarpado & 110 & 0,1 \\
\hline Total & & 88.001 & 100 \\
\hline
\end{tabular}

\section{Geologia}

Em relação às características geológicas, o município de Pombal - PB, está inserido na unidade geoambiental da Depressão Sertaneja, caracterizada por uma superfície de pediplanação monótona (CPRM, 2005), com relevo predominantemente suave-ondulado, cortado por vales estreitos, observando-se, de forma isolada na linha do horizonte, elevações residuais, testemunhos dos ciclos intensos de erosão que atingiram grande parte dessa região (EMBRAPA, 2002).

A limitação mais importante em toda Depressão Sertaneja é a condição do clima semiárido quente, com chuvas escassas e muito irregulares que restringe drasticamente a agricultura dependente de chuva (ARAUJO FILHO, 2011), além de solos rasos, pedregosos e de origem cristalina, com fertilidade média a alta, sofrendo facilmente com processos erosivos.

\section{Solos}

No que se refere aos aspectos pedológicos do município de Pombal - PB, conforme ilustrado na Figura 
5, observa-se que o tipo de solo predominante é do tipo Luvissolo Crômico - LC, com 71,5\% (641km²), seguido do Neossolo litólico com 20,6\% (185 km²). Além disso, apresentam-se delimitações de solo do tipo Neossolo Flúvico - NF, Argissolo vermelho e Amarelo - AVA, Planossolo Nátrico - PN, com 2,7\% (24 km²), $1 \%\left(9 \mathrm{~km}^{2}\right)$ e $3,8 \%\left(34 \mathrm{~km}^{2}\right)$, respectivamente.

Segundo Gomes et al. (2017), os solos do tipo Luvissolos Crômicos, são solos minerais, não hidromórficos, de textura média no horizonte A e argiloso no B e ficam situados em localidades que apresentam basicamente relevo ondulado. Estes solos são caracterizados pela baixa profundidade, por fertilidade regular e alta erodibilidade.

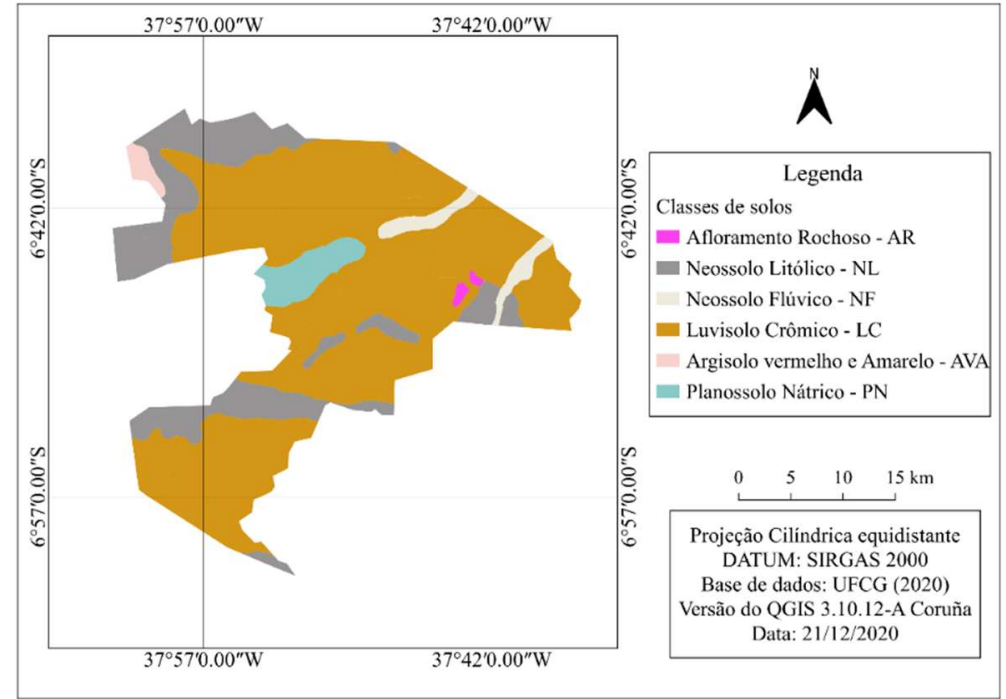

Figura 5: Mapa do tipo de solo no município de Pombal - PB.

Vale ressaltar, que as atividades agropecuárias juntamente com a crescente urbanização na AID, tem contribuído para a degradação da APP, principalmente no trecho urbano, onde apresenta-se uma intensa redução da flora riparia, deixando o solo praticamente sem cobertura vegetal, conforme ilustrado na Figura 6.

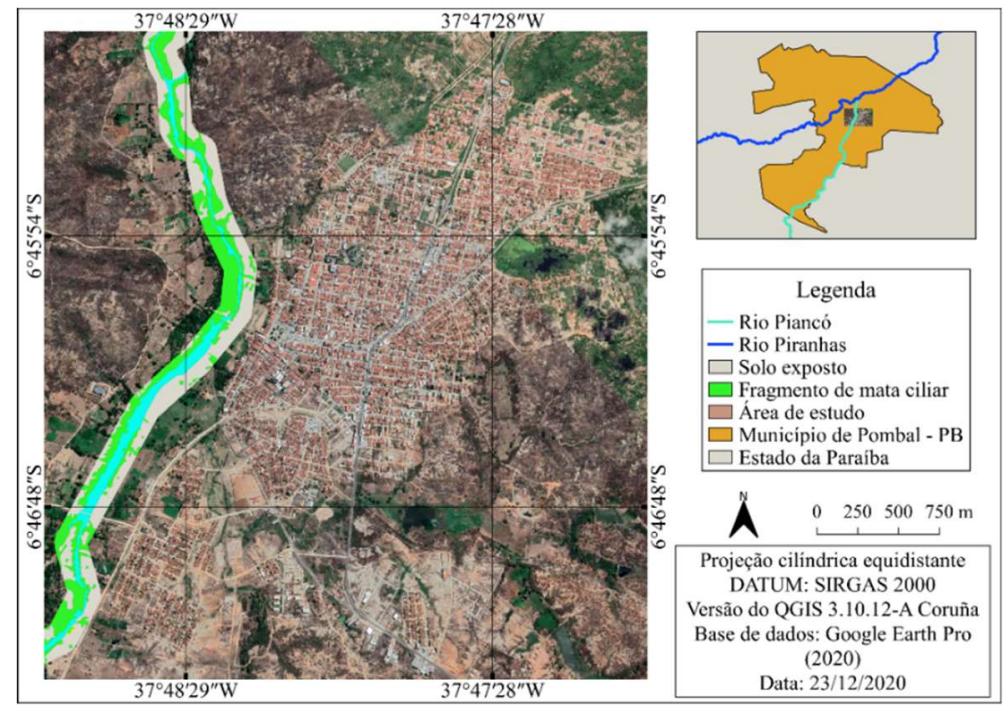

Figura 6: Áreas com solo exposto na AID do estudo.

Na Figura 7, apresenta-se em porcentagem a relação entre a mata ciliar com o solo exposto da AID 
do estudo, com dados extraídos da Figura 6.

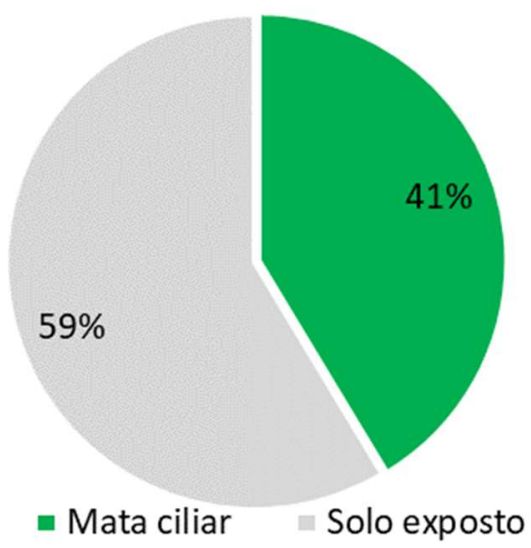

Figura 7: Percentual da mata ciliar em relação ao solo exposto na AID.

Na Figura 7, verifica-se que 59\% da APP do Rio Piancó do trecho urbano de Pombal - PB possui solo exposto, sendo que, $41 \%$, é fragmento de mata ciliar da cobertura original da referida área. Desta forma, o solo torna-se vulnerável aos efeitos dos agentes naturais (chuvas, raios solares, ventos, entre outros) e às ações antrópicas, sendo a causa principal desse processo de degradação ambiental da APP, tornando-o mais susceptível à processos erosivos, além disso, o solo apresenta sinais de revolvimento e compactação, conforme ilustrado nas figuras $8 \mathrm{~A}, 8 \mathrm{~B}, 8 \mathrm{C}$ e $8 \mathrm{D}$.
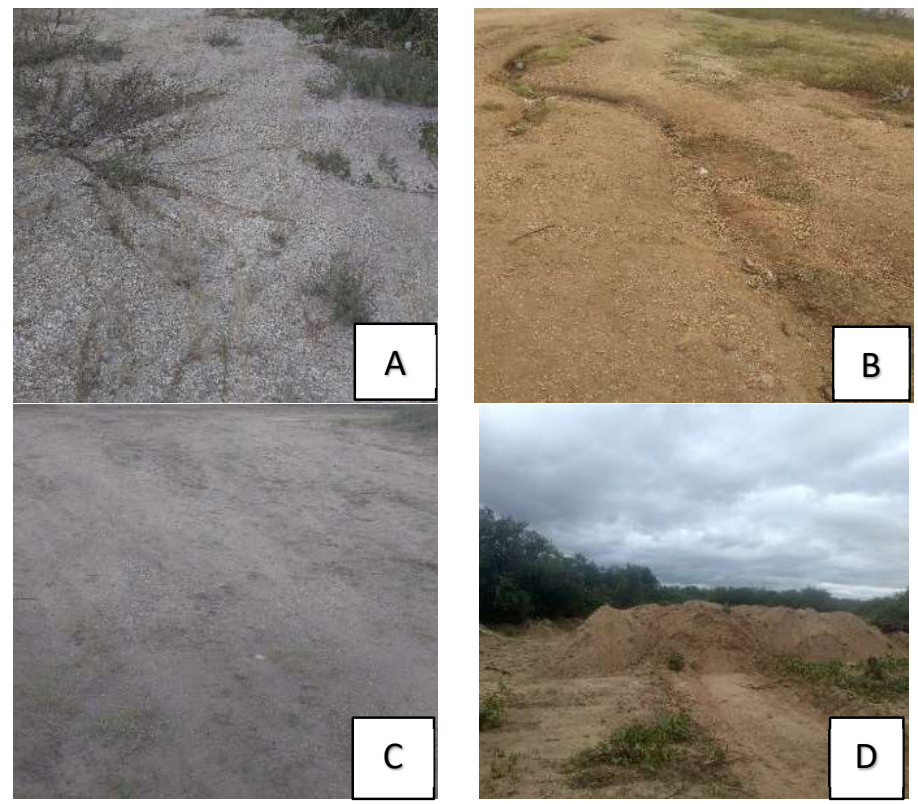

Figura 8: Erosão hídrica laminar (A); Erosão hídrica em sulcos (B); Solo exposto e compactado (C); Revolvimento da camada superficial do solo (D).

\section{Recursos hídricos}

No que se refere aos corpos d'água superficiais da área de estudo, na Figura 9, apresentam-se os principais corpos d'água do município de Pombal - PB. 


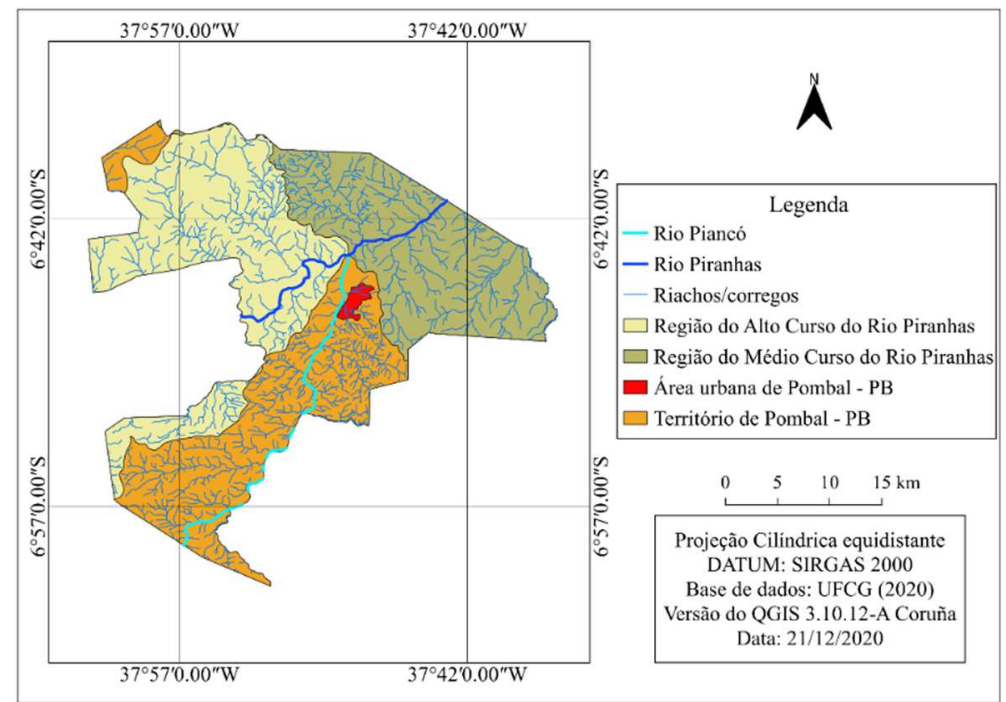

Figura 9: Mapa hidrológico do município de Pombal - PB.

Conforme observado na Figura 9, destacam-se o rio Piranhas e o Piancó, que cortam a área urbana de Pombal - PB, sendo perenizado pelo Sistema Hídrico Curema-Mãe D’água.

Ao longo de toda extensão do rio Piancó são realizadas atividades antrópicas com potencial impactante para os componentes ambientais (água, solo, ar atmosférico, mata ciliar, entre outros), principalmente no trecho que corta a área urbana de Pombal - PB. Diante do exposto, as principais atividades poluidoras identificadas na APP do rio que corta a área urbana do município de Pombal - PB são: Despejo de esgoto, pecuária bovina no modelo extensivo, Área de lazer e urbanização, conforme ilustrado nas Figuras $10 a, 10 b, 10 c$ e $10 d$, respectivamente.

Em um estudo realizado por Ismael et al. (2019), em todo o percurso do Rio Piancó, eles realizaram a catalogação de vária atividades antrópicas poluidoras e com potencial poluidor, dentre elas, destacam-se a pecuária extensiva, cultivo de pastagem, desmatamento da mata ciliar e outras áreas, recreação, agricultura, urbanização, extração de areia e irrigação.
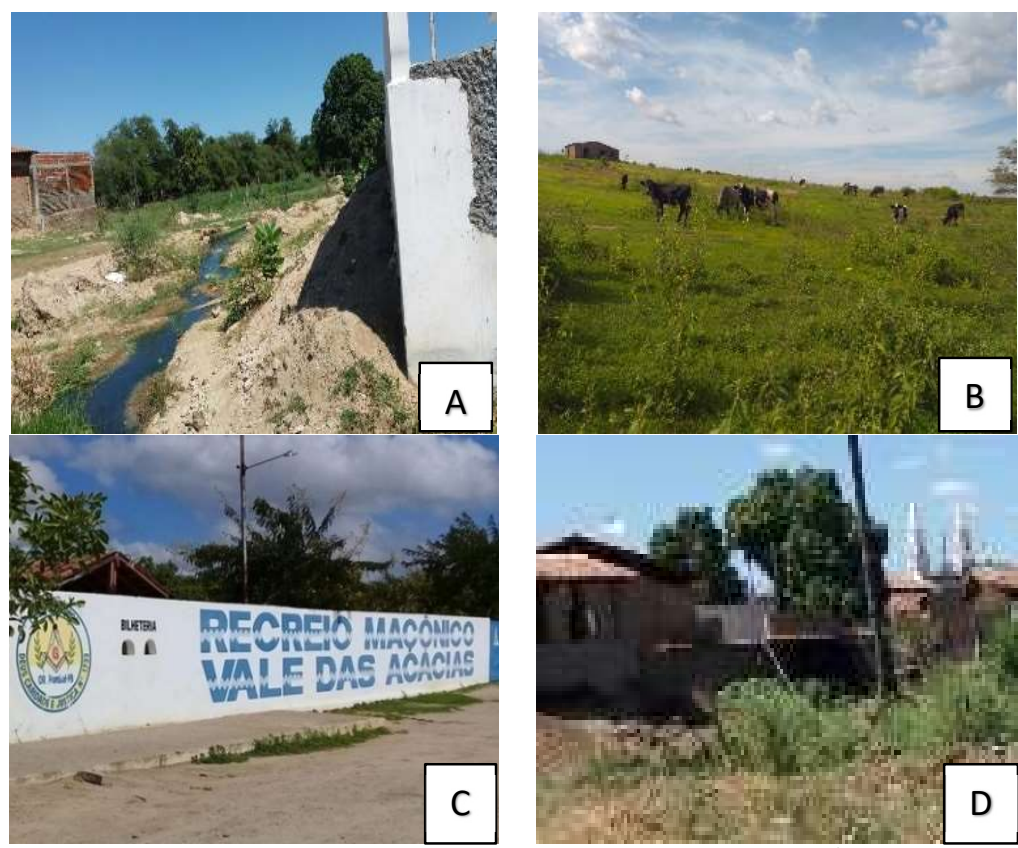

Figura 10: Despejo de esgoto no rio Piancó (A); Pecuária bovina extensiva (B); Área de lazer (C); urbanização (D). 
Na Figura 10A, observa-se efluentes não tratados lançados sobre o solo, sendo escoado e introduzido nas águas do rio Piancó, alterando a qualidade da água, assim, acarretando diversos impactos negativos para o meio aquático do rio. Além disso, na Figura 10B, observa-se a atividade de pecuária bovina no modelo extensivo, a qual possui grande potencial impactante para o meio ambiente, principalmente para os recursos hídricos, devido ao manejo inadequado dos resíduos gerados e a destruição da vegetação nativa, assim como, a mata ciliar, para a utilização agropecuária.

Nas Figuras 10C e 10D, verifica-se as atividades de área de recreação e urbanização, sendo a mesma a mais impactada entre os componentes/elementos ambientais, como, por exemplo, a destruição da vegetação natural devido à expansão urbana, ocasionando diversos impactos ambientais negativos, entre eles, destacam-se, a modificação da paisagem natural da área.

Outrossim Almeida Junior et al. (2017), a disposição dos esgotos no trecho urbano do Rio Piancó é um dos principais fatores de degradação da qualidade ambiental das águas do referido rio, conforme ilustrado na figura 11. Além disso, os autores supracitados afirmam que essa poluição é resultante da falta do sistema de esgotamento sanitário, o que acarreta diversos impactos ambientais adversos, como a eutrofização das águas.

Segundo Pinto et al. (2020), a eutrofização é um problema ambiental que afeta os ecossistemas de água doce por todo o mundo, como lagos e rios. Este processo provém do enriquecimento em nutrientes no meio aquático (principalmente compostos de Nitrogênio e Fósforo), que resulta essencialmente de lixiviados de solos agrícolas, descargas urbanas e industriais ou da criação de gado.

O processo de eutrofização, há uma tendência para a formação e crescimento exacerbado de microalgas o que acarreta diversas alterações nos corpos hídricos como, o aumento da turbidez da água, depleção da concentração de oxigénio e reduzem a biodiversidade, e a própria degradação do ecossistema aquático, como pode ser observado na figura 12, o que pode ocasionar custos aos cofres públicos com ações de recuperação ambiental desse componente ambiental.

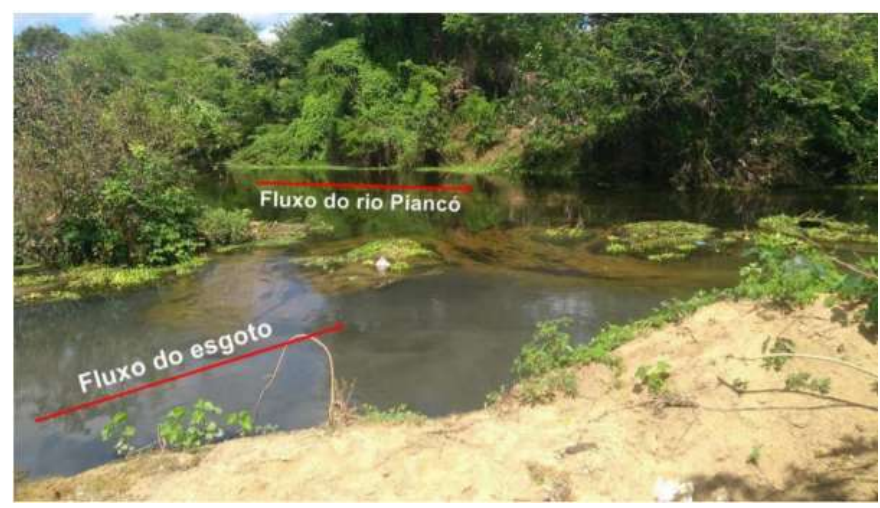

Figura 11: Disposição dos esgotos no Rio Piancó no trecho urbano do município de Pombal - PB. Fonte: Almeida Junior et al. (2017).

Na figura 12, observa-se a presença de vegetação aquática nas águas do Rio Piancó, representadas por macrófitas aquáticas e flutuantes, cobrindo grande extensão do referido rio, acarretando diversos impactos ambientais negativos, como: eutrofização, redução da vazão, morte dos seres vivos aquáticos, 
dentre outros (ALMEIDA JUNIOR et al., 2017).

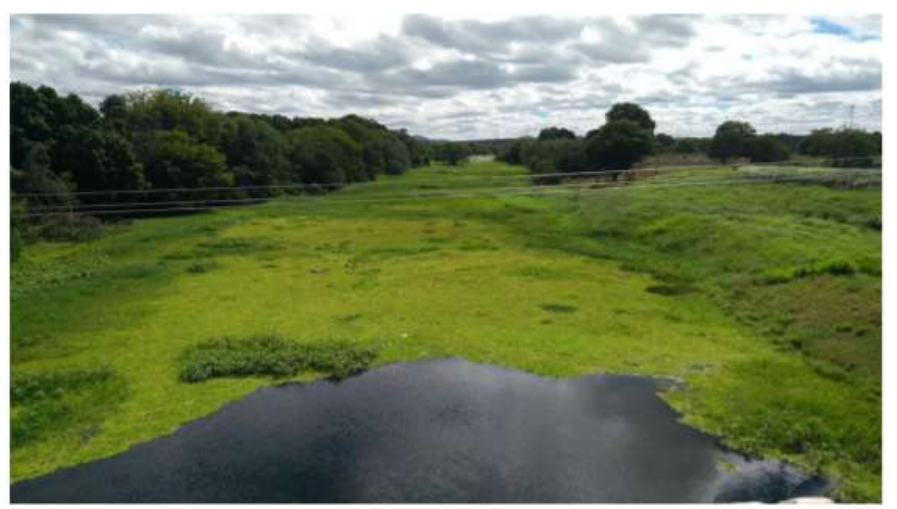

Figura 12: Presença de vegetação aquática cobrindo grande extensão do rio Piancó. Fonte: Almeida Junior et al. (2017).

Conforme a figura 12, e segundo Azevedo et al. (2015) o Rio Piancó é perenizado, possui mata ciliar degrada na maior parte do seu comprimento e encontra-se eutrofizado. Entre os principais problemas de qualidade da água, a eutrofização é o mais comum (MOAL et al., 2019). Assim, a preocupação com a qualidade da água, se justifica pela facilidade em que as suas propriedades podem ser modificadas, fatores endógenos e exógenos ao meio ambiente, causam mudanças nos parâmetros qualitativos da água e geram prejuízos para população (VON SPERLING et al., 2008).

Para sanar estes impactos ambientais, é de fundamental importância que seja implantado nos municípios que ficaram na bacia hidrográfica do Rio Piancó o sistema de coleta e tratamento e esgotos sanitários, como também a captação e tratamento do lixiviado dos lixões a céu aberto, aliada de um monitoramento do nível de poluição desse corpo hídrico, garantindo a qualidade ambiental do manancial, e a preservação da saúde e do bem-estar da população.

\section{Paisagem}

$\mathrm{Na}$ área de influência do estudo foram observadas paisagens "naturais" e "antropizadas", conforme ilustrado nas Figuras 13A e 13B.
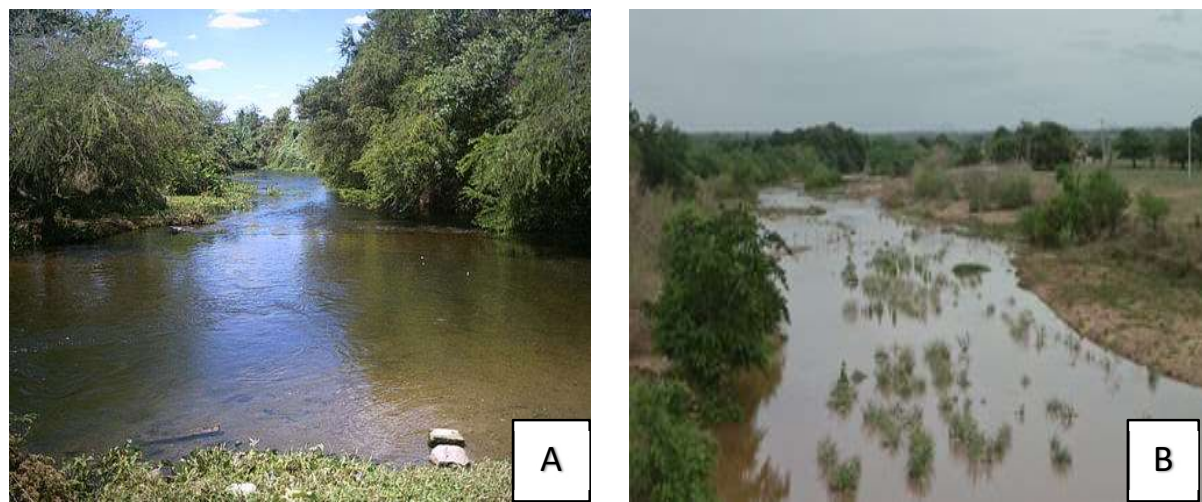

Figura 23: Paisagem “natural” (A); Paisagem “antropizada” na APP do Rio Piancó (B).

Na APP do Rio Piancó, há uma diversidade de paisagens "naturais" e "antropizadas". Com relação aos ambientes naturais encontrados, principalmente alguns fragmentos de mata ciliar localizadas em 
algumas partes do trecho perenizado do referido rio, estando em estado adequado de conservação, conforme ilustrado na Figura 13a.

Em relação as paisagens antropizadas identificadas, destacam-se as áreas onde ocorrerama destruição da mata ciliar, realizada pelas atividades de agropecuária, para o plantio de culturas forrageiras para a alimentação dos rebanhos de gados, conforme apresentado na Figura 13b.

\section{Meio Biótico}

\section{Ecossistema}

Ecossistema ou sistema ecológico é qualquer ambiente onde há a interação entre o meio abiótico (natureza solar, luminosidade, temperatura, pressão, água, umidade do ar, salinidade) e o biótico (seres vivos) se constituem num ecossistema, seja ele terrestre ou aquático, grande ou pequeno (RAMOS et al., 2010).

Portanto, um ecossistema possui dimensões variadas, pode ser constituído por uma floresta inteira, num grande espaço, "macro-ecossistema", ou por uma planta a exemplo das bromélias, pequeno espaço, chamado "micro-ecossistema". Nesses dois tipos de ecossistemas todos possuem os fenômenos e fatores que delimitam e definem o ambiente dos seres vivos (RAMOS et al., 2010).

Em relação aos ecossistemas naturais predominantes na área de estudo, destacam-se os típicos do bioma Caatinga. Segundo a CPRM (2005), no município de Pombal - PB há a predominância de vegetação da Caatinga Hiperxerófila com trechos de Floresta Caducifólia.

Segundo Ramos et al. (2020) o bioma Caatinga apresenta grandes níveis de degradação, ocupando as áreas nordestinas e uma parte do norte de Minas Gerais. Esse bioma vem sendo submetido a altas taxas de antropização e já apresenta núcleos de desertificação, que prejudica a própria flora, a fertilidade do solo e a fauna.

\section{Flora}

No que diz respeito à flora na área de influência, verificou-se diferentes conjunções de flora, entre espécies nativas e exóticas do bioma caatinga, e a partir de um diagnóstico ambiental simplificado da flora local, identificaram-se as principais espécies florestais. Na Tabela 6 e nas Figuras 14A a 14F estão apresentadas as principais espécies florestais nativas identificadas na área de influência do estudo.

Tabela 6: Espécies florestais nativas identificadas na área de influência do estudo.

\begin{tabular}{llll}
\hline Família & Nome científico & Nome popular & Figura \\
\hline Chrysobalanaceae & Licania rigida & Oiticica & $13 \mathrm{~A}$ \\
\hline Rhamnaceae & Ziziphus joazeiro Mart. & Juazeiro & $13 \mathrm{~B}$ \\
\hline Bignoniaceae & Tabebuia aurea & Craibeira & $13 \mathrm{C}$ \\
\hline Fabaceae & Mimosa tenuiflora & Jurema preta & $13 \mathrm{D}$ \\
\hline \multirow{3}{*}{ Cactaceae } & Pilosocereus gounellei & Xique-xique & $13 \mathrm{E}$ \\
\cline { 2 - 4 } & Cereus jamacaru & Mandacaru & $13 \mathrm{~F}$ \\
\hline
\end{tabular}



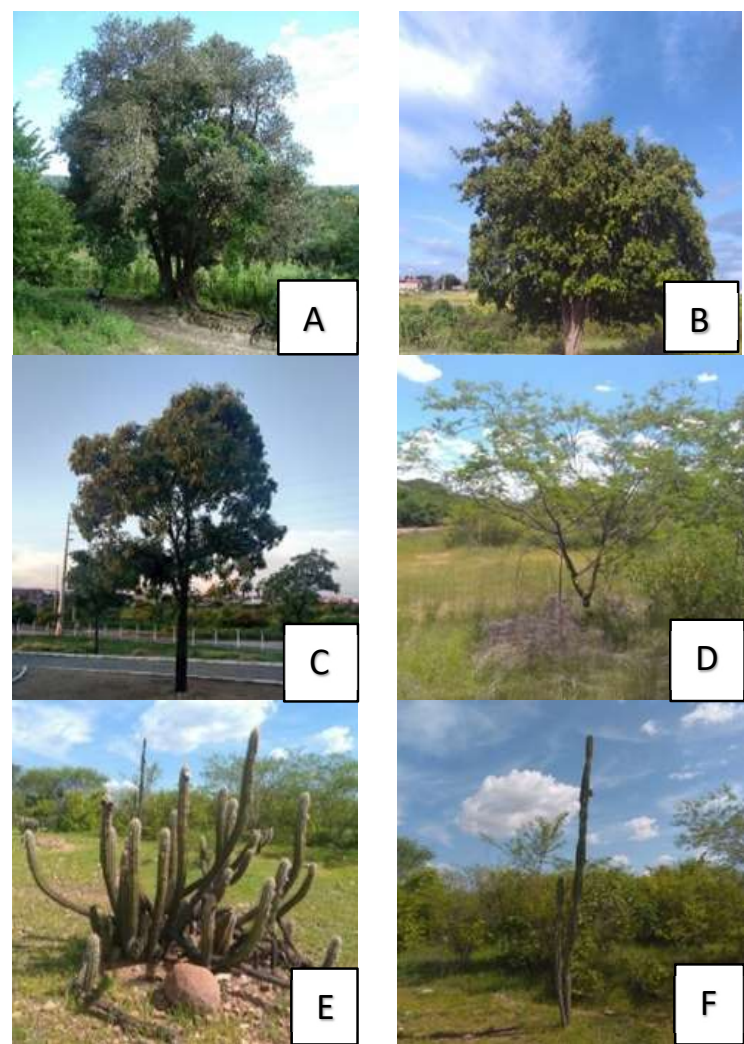

Figura 14: Espécies florestais nativas diagnosticadas na área de influência do estudo.

Na Tabela 7 e nas Figuras 15A a 15D encontram-se apresentadas as principais espécies florestais exóticas identificadas na área de influência do estudo.

Tabela 7: Espécies florestais exóticas identificadas na área de influência do estudo.

\begin{tabular}{llll}
\hline Família & Nome científico & Nome popular & Figura \\
\hline Leguminosae & Prosopis juliflora & Algaroba & $14 \mathrm{~A}$ \\
\hline Combretaceae & Terminalia catappa & Castanhola & $14 \mathrm{~B}$ \\
\hline Meliaceae & Azadirachta indica & Nim & $14 \mathrm{C}$ \\
\hline Moringaceae & Moringa oleifera & Moringa & $14 \mathrm{D}$ \\
\hline
\end{tabular}
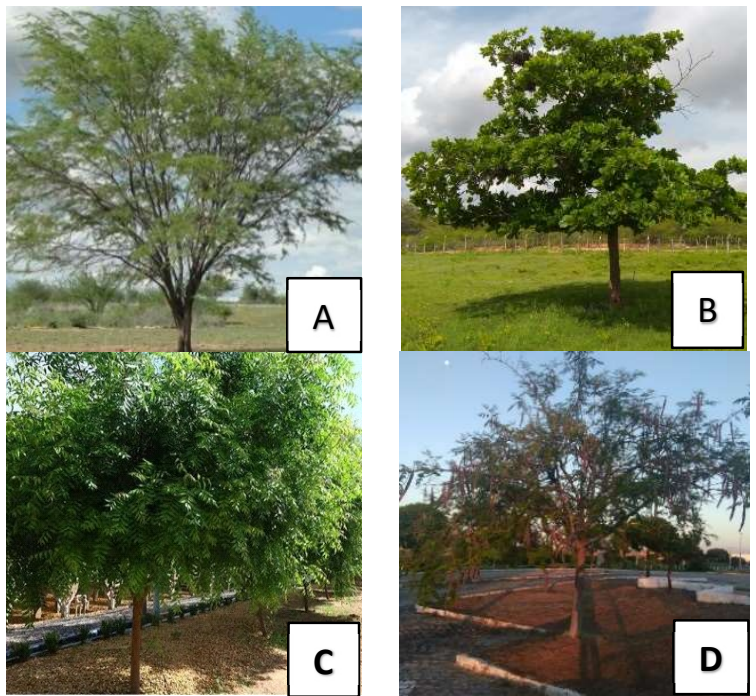

Figura 15: Espécies florestais exóticas identificadas na área de influência do estudo.

Em estudo realizado por Gomes et al. (2017), numa área pertencente ao município de Pombal-PB, verificou-se, a partir de um diagnóstico ambiental simplificado da flora local, que as principais espécies vegetais encontradas foram: Jurema-preta (Mimosa hostilis), Angico branco (Anadenanthera colubrina) 
Algaroba (Prosopis juliflora), Mandacaru (Cereus jamacaru) e Xique-xique (Pilosocereus gounelleii).

\section{Fauna}

Em relação à fauna na área de influência do estudo, observou-se espécies silvestres e domesticadas. Além disso, verificou-se que as espécies endêmicas de animais da APP do Rio Piancó encontram-se reduzida e até extinta, devido à destruição da mata ciliar juntamente com seus componentes ambientais que possibilitam a vida de algumas espécies nesse local, obrigando-os a dispersarem para outras regiões aumentando o desequilíbrio natural.

Na Tabela 8 e nas Figuras 16A a 16D encontram-se apresentadas as principais espécies animais silvestres identificadas na área de influência do estudo.

Tabela 8: Espécies animais silvestres identificadas na área de influência do estudo.

\begin{tabular}{llll}
\hline Família & Nome científico & Nome popular & Figura \\
\hline Falconidae & Caracara plancus & Carcará & $15 \mathrm{~A}$ \\
\hline Columbidae & Columbina picui strepitans & Rolinha da caatinga & $15 \mathrm{~B}$ \\
\hline Cuculidae & Crotophaga ani & Anu-preto & $15 \mathrm{C}$ \\
\hline Strigidae & Glaucidium brasilianum & Coruja & $15 \mathrm{D}$ \\
\hline
\end{tabular}
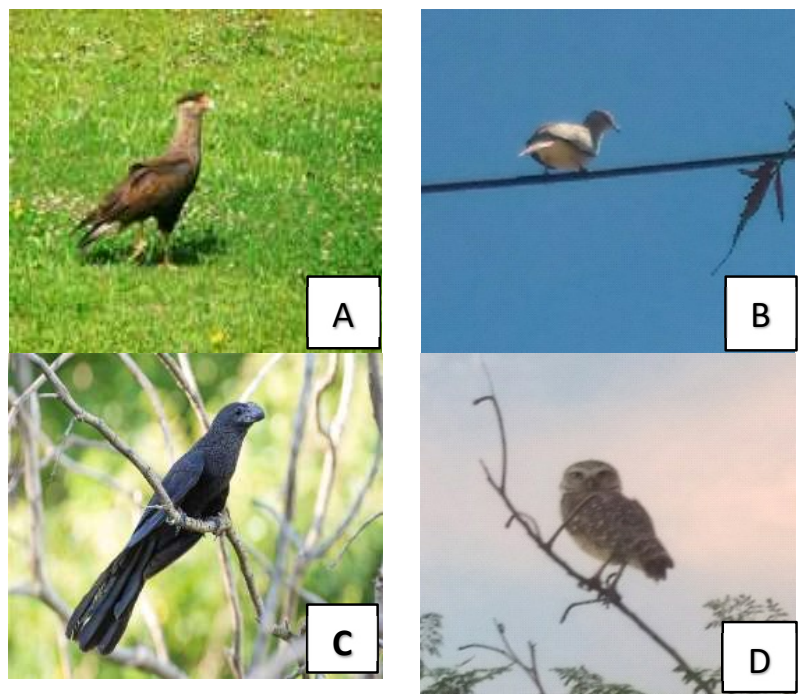

Figura 16: Espécies animais silvestres identificadas na área de influência do estudo.

Na Tabela 9 e nas Figuras 17A a 17D encontram-se apresentadas as principais espécies animais domesticadas identificadas na área de influência do estudo.

Tabela 9: Espécies animais domesticados identificadas na área de influência do estudo.

\begin{tabular}{llll}
\hline Família & Nome científico & Nome popular & Figura \\
\hline Suidae & Sus scrofa domesticus & Porco & $16 \mathrm{~A}$ \\
\hline Phasianidae & Gallus gallus domesticus & galo/galinha & $16 \mathrm{~B}$ \\
\hline Numididae & Numida meleagris & Galinha-d'angola ou Guiné ou capote & $16 \mathrm{C}$ \\
\hline Bovidae & Bos taurus & touro & $16 \mathrm{D}$ \\
\hline
\end{tabular}



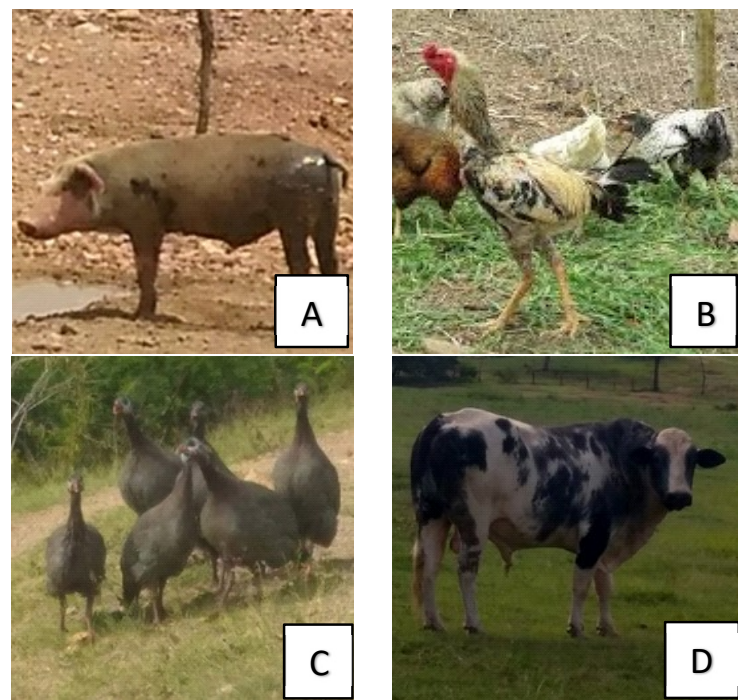

Figura 17: Espécies animais domésticos identificadas na área de influência do estudo.

\section{Meio Antrópico}

\section{População}

Com relação aos aspectos populacionais do município de Pombal - PB, a população estimada para o município no ano de 2020 foi aproximadamente 32.802 habitantes, de acordo com o censo demográfico do IBGE (2010). Na Tabela 10, apresentam-se dados demográficos do município de Pombal - PB, referentes ao ano de 2010, segundo informações do IBGE (2010).

Tabela 10: Dados populacionais do município de Pombal - PB.

\begin{tabular}{ll}
\hline População referente ao ano $\mathbf{2 0 1 0}$ & Pombal - PB \\
\hline Urbana (hab.) & 25.753 \\
Rural (hab.) & 6.357 \\
Total (hab.) & 32.110 \\
Homens (hab.) & 15.381 \\
Mulheres (hab.) & 16.729 \\
Densidade demográfica (hab./ $\mathrm{km}^{2}$ ) & 36,13 \\
\hline
\end{tabular}

Fonte: Elaborado com base nos dados do IBGE (2010).

Em 2010 (Tabela 10), o município de Pombal - PB tinha população superior a 32 mil habitantes, constituída por $52 \%$ de mulheres e $48 \%$ de homens, e concentrava-se na zona urbana (80\%). Vale ressaltar, que este município está entres os mais populosos da Região geográfica intermediária de Patos - PB, ocupando a quinta posição, atrás da cidade de Patos, Sousa, Cajazeiras e São Bento, sendo a cidade de Patos detentora do maior número de pessoas, com estimativa para o ano de 2020 de 108.192 habitantes (IBGE, 2010).

\section{Economia}

No que tange a economia do munícipio de Pombal - PB, de acordo com o censo agropecuário realizado pelo IBGE (2017), verifica-se que a atividade econômica predominante na maior parte do território é a agropecuária. As atividades pecuárias que são mais desenvolvidas são, respectivamente: bovina, ovina e galinácea. Em relação a APP do Rio Piancó no trecho da área urbana do município de Pombal - PB, a partir das visitas in loco, verificou-se que as principais atividades econômicas realizadas nesse local é a pecuária bovina, irrigação de capim, desmatamento, extração de areia no leito do rio. 
Ismael et al. (2019) realizaram um estudo ao longo do trecho perenizado do Rio Piancó, onde foi possível identificar as principais atividades antrópicas desenvolvidas, destacando-se a agricultura irrigada/sequeiro e pecuária bovina extensiva. Segundo o autor, as atividades agrícolas ocasionam diversos impactos ambientais devido, principalmente, a retirada da mata ciliar, isto pode ser atribuído ao fato que parte dos trabalhadores agrícolas desconhece os riscos ambientais que algumas práticas ofertam aos ecossistemas.

\section{CONCLUSÕES}

O diagnóstico ambiental simplificado dos meios físico, biótico e antrópico da APP do rio Piancó no trecho urbano do município de Pombal - PB indicou que todos os fatores ambientais estudados na área de influência direta encontram-se impactados negativamente, e grande parte, a exemplo do solo e da flora, estão degradados.

Os principais impactos negativos identificados na APP do Rio Piancó foi a eutrofização das águas, ocasionada pelo lançamento de efluentes não tratados no corpo hídrico, e a erosão do solo. Tal situação de degradação ambiental na área de estudo é decorrente das atividades antrópicas realizadas nesse local, destacando-se o avanço da urbanização e pecuária.

Por fim, espera-se que os resultados alcançados deste estudo sirvam como base técnica e cientifica para os próximos estudos futuros na APP do rio Piancó, principalmente no trecho urbano de Pombal - PB.

\section{REFERÊNCIAS}

ALEMU, T.; BAHRNDORFF, S.; HUNDERA, K.; ALEMAYEHU, E.; AMBELU, A.. Effect of riparian land use on environmental conditions and riparian vegetation in the east African highland streams. Limnologica, v.66, p.1-11, 2017. DOI: https://doi.org/10.1016/j.limno.2017.07.001

ALMEIDA JUNIOR, M. A. B. A; ALMEIDA, R. S.; SILVA, G. O. C.. Diagnóstico dos impactos ambientais provocados pelo lançamento de esgotos no rio Piancó em Pombal-PB. Revista Geociências, v.2, n.3, 2017.

ARAUJO FILHO, J. C. A.. Relação solo e paisagem no Bioma Caatinga. In: SIMPÓSIO BRASILEIRO DE GEOGRAFIA FÍSICA APLICADA, Anais. Dourados: UFGD, 2011.

AZEVEDO, P. B.; LEITE, J. C. A.; OLIVEIRA, W. S. N.; SILVA, F. M.; FERREIRA, P. M. L.. Diagnóstico da degradação ambiental na área do lixão de Pombal - PB. Revista Verde de Agroecologia e Desenvolvimento Sustentável, v.10, n.1, p.20-34, 2015. DOI:

https://doi.org/10.18378/rvads.v10i1.3294

BRASIL. Leis e Decretos. Lei Federal n.12.651, de 25 de maio de 2012. Institui o Novo Código Florestal Brasileiro. Brasília: DOU, 2012.

CORREIA, I. M. G.; SOUZA, B. H.; MOURA, D. C.; SOUZA, Y. G.. Mata ciliar, conservação e sustentabilidade, fundamentos da importância para o semiárido paraibano: estudo de caso no alto curso do Rio Paraíba. Revista de Geociências do Nordeste, v.5, n.2, p.41-60, 2019. DOI:
https://doi.org/10.21680/2447-3359.2019v5n2ID17233

CASTRO, J. L. S.; FERNANDES, L.; FERREIRA, K.; TAVARES, M. A. S.; ANDRADE, J.. Mata cilar: importancia e funcionamento. In: CONGRESSO BRASILEIRO DE GESTÃO AMBIENTAL, 8. Anais. Campo Grande, 2017.

CPRM. Companhia de Pesquisa de Recursos Minerais. Projeto cadastro de fontes de abastecimento por água subterrânea: diagnóstico do município de Pombal. Recife: CPRM/PRODEEM, 2005.

EMBRAPA. Empresa Brasileira de Pesquisa Agropecuária. Aspectos Agro e Zooecológicos. EMBRAPA, 2002.

GARCIA, Y. M.; CAMPOS, S.; TAGLIARINI, F. S. N.; CAMPOS, M.; RODRIGUES, B. T.. Declividade e potencial para mecanização agrícola da bacia hidrográfica do Ribeirão, Pederneiras/SP.Revista Brasileira de Engenharia de Biossistemas, v.14, n.1, p.62-72, 2020. DOI: https://doi.org/10.18011/bioeng2020v14n1p62-72.

ISMAEL, F. C. M.; LEITE, J. C. A.; ISMAEL, D. A. M.; SILVA, E. F.; FREITAS, G. P.; SOUSA, T. M. I.. Identificação de impactos ambientais nas águas do trecho perenizado do Rio Piancó. Revista em Agronegócio e Meio Ambiente, v.12, n.3, p.9991017, 2019. DOI: https://doi.org/10.17765/21769168.2019v12n3p999-1017.

IBGE. Instituto Brasileiro de Geografia e Estatística. Bases e referenciais: bases cartográficas. Brasília: IBGE, 2015. 
IBGE. Instituto Brasileiro de Geografia e Estatística. Banco de dados agregados: censo demográfico. Brasília: IBGE, 2010.

IBGE. Instituto Brasileiro de Geografia e Estatística. Banco de dados agregados: censo agropecuário. Brasília: IBGE, 2017.

MOAL, M. L.; GASCUEL-ODOUX, C.; MÉNESGUEN, A.; SOUCHON, Y.; ÉTRILLARD, C.; LEVAIN, A.; MOATAR, F.; PANNARD, A.; SOUCHU, P.; LEFEBVRE, A.; PINAY, G.. Eutrophication. A new wine in an oldbottle?. Science of the Total Environment, v.651, p.1-11, 2019. DOI: http://doi.org/10.1016/j.scitotenv.2018.09.139

GOMES, N. A.; LEITE, J. C. A.; FARIAS, C. A. S.; SILVA, A. P. O.; ISMAEL, F. C. M.. Diagnóstico ambiental qualitativo no "Iixão" da cidade de Pombal, Paraíba. Revista Verde de Agroecologia e Desenvolvimento Sustentável, v.12, n.1, p.61-67, 2017. DOI:

https://doi.org/10.22533/at.ed.5891908032

PINTO, F.; ANTUNES, S. C.. Biomanipulação para o controlo da eutrofização. Revista de Ciência Elementar, v.8, n.1, 2020. DOI: http://doi.org/10.24927/rce2020.010
RAMOS, G. G.; ALVES, J. B.; ARAÚJO, M. D. F.; FERREIRA, V. S. G.; PINTO, M. G. C.; LEITE, M. J. H.; VASCONCELOS, A. D. M.; RIBEIRO, I. R.. Levantamento dos impactos ambientais de um trecho de mata ciliar em região de Caatinga no sertão paraibano. Brazilian Journal of Development, v.6, n.7, p.52848-52859, 2020. DOI: https://doi.org/10.34117/bjdv6n7-798.

RAMOS, M. G. O.; AZEVEDO, M. R. Q. A.. Ecossistemas Brasileiros: definição de ecossistemas. Campina Grande: EdUEPB; Natal: EDUFRN, 2010.

VALLADARES, G. S.; GOMES, A. S.; TORRESAN, F. H.; RODRIGUES, C. A. G.; GREGO, C. R.. Modelo multicritério aditivo na geração de mapas de suscetibilidade à erosão em área rural. Pesquisa Agropecuária Brasileira, v.47, n.9, p.1376-1383, 2012. DOI: https://doi.org/10.1590/S0100$\underline{204 \times 2012000900023}$

VON SPERLING, E.; FERREIRA, A. C. S.; GOMES, L. N. L.. Comparative eutrophication development in two Brazilian water supply reservoirs with respect to nutrient concentrations and bacteria growth. Desalination, v.226, n.1-3, p.169-174, 2008. DOI: https://doi.org/10.1016/j.desal.2007.02.105

A CBPC - Companhia Brasileira de Produção Científica (CNPJ: 11.221.422/0001-03) detém os direitos materiais desta publicação. Os direitos referem-se à publicação do trabalho em qualquer parte do mundo, incluindo os direitos às renovaç̃oes, expansões e disseminações da contribuiç̃o, bem como outros direitos subsidiários. Todos os trabalhos publicados eletronicamente poderão posteriormente ser publicados em coletâneas impressas sob coordenação da Sustenere Publishing, da Companhia Brasileira de Produção Científica e seus parceiros autorizados. Os (as) autores (as) preservam os direitos autorais, mas não têm permissão para a publicação da contribuição em outro meio, impresso ou digital, em português ou em tradução. 